\title{
Liquid-Liquid Equilibria for Ternary Mixtures Containing Vegetable Oils, Methanol, and Cosolvents
}

\author{
Ming-Jer Lee*,a, Yu-Ching Kuo ${ }^{\mathrm{a}}$, Pei-Jung Lien ${ }^{\mathrm{b}}$ and Ho-Mu Lin ${ }^{\mathrm{a}}$ \\ ${ }^{a}$ Department of Chemical Engineering, National Taiwan University of Science and Technology, 43 Keelung Road, \\ Section 4, Taipei 106-07, Taiwan \\ ${ }^{b}$ Energy and Agile System Department, Metal Industries Research \& Development Centre1001 Kaonan Highway, \\ Kaohsiung 811, Taiwan
}

\begin{abstract}
The liquid-liquid equilibrium (LLE) phase boundaries were determined experimentally for the ternary systems containing refined sunflower oil, methanol, and one of ten potential cosolvents at $308.2 \mathrm{~K}$ under atmospheric pressure by using cloud point method. $n$-Butylamine was found to be one of the best cosolvents, which could substantially enhance the miscibility between the oil and methanol. The LLE measurements were then extended to the ternary systems of methanol + refined sunflower oil, soybean oil, or canola oil in the presence of the auxiliary cosolvent $n$-butylamine at temperatures from $298.2 \mathrm{~K}$ to $318.2 \mathrm{~K}$. The LLE data were utilized for estimating the model parameters of the NRTL and the UNIQUAC, respectively. In general, these two models can reasonably represent the LLE phase boundaries.
\end{abstract}

Keywords: Liquid-liquid equilibria, vegetable oils, methanol, cosolvents.

\section{INTRODUCTION}

In recent years, biodiesel has been recognized as one of cleaner fuels produced from renewable resources [1-3]. The major compounds of the biodiesel are fatty acid methyl esters (FAME), which typically can be obtained via transesterification of oils or fats with methanol. In the transesterification, the reactants (oils and methanol) are partially miscible. To promote the reaction rate by means of reducing the masstransfer resistance between the reacting constituents, several auxiliary cosolvents have been suggested. Those potential cosolvents include tetrahydrofuran, ethyl acetate, dimethyl ether, diethyl ether, 1,4-dioxane, 4-methylpiperidine, $\mathrm{N}, \mathrm{N}$ dimethyltrimethylenediamine, diethylamine, tetramethyldiaminoethane, dimethylethanolamine, and tetramethylammonium hydroxide as $25 \%$ solution in methanol [4-8]. Boocock et al. [6] found that the methanolysis of oil was dramatically enhanced in a single phase by adding cosolvent tetrahydrofuran. Similar results were also disclosed by Cerce et al. [7] who used tetramethylammonium hydroxide as a cosolvent and a basic catalyst, simultaneously.

In the present study, ten organic solvents, including acetone, methyl ethyl ketone, methyl acetate, ethyl acetate, methyl propionate, propylene glycol monomethyl ether acetate, dimethyl carbonate, tetrahydrofuran, methyl tert-butyl ether, and $n$-butylamine, were selected to test their capability for improving the miscibility between refined sunflower oil and methanol via a series of LLE measurements at $308.2 \mathrm{~K}$ under atmospheric pressure. The effects of the presence of $n$ butylamine on the LLE behavior were further investigated

\footnotetext{
*Address correspondence to this author at the Department of Chemical Engineering, National Taiwan University of Science and Technology, 43 Keelung Road, Section 4, Taipei 106-07, Taiwan; Tel: +886-2-2737-6626; Fax: +886-2-2737-6644; E-mail: mjlee@mail.ntust.edu.tw
}

for refined soybean oil/methanol and refined canola oil/methanol systems. These new LLE data are useful in the determination of the parameters of activity coefficient models, the NRTL [9] and the UNIQUAC [10], for properly describing the non-ideality of the constituent compounds in the liquid phases. Those model parameters are essentially needed for the development of biodiesel production processes.

\section{EXPERIMENTAL SECTION}

\subsection{Materials}

Methanol (99.9\%), acetone (99.5\%), dimethyl carbonate (DMC, $99 \%)$, ethyl acetate $(99.5 \%)$, methyl acetate $(99.5$ $\%)$, methyl ethyl ketone (MEK, $99 \%$ ), methyl propionate (98\%), n-butylamine (99\%), tetrahydrofuran (THF, 99.5 $\%)$, and glycerol (99\%) were purchased from Acros, USA. Propylene glycol monomethyl ether acetate $(98+\%)$ was supplied by Aldrich, USA. Methyl tert-butyl ether (99 \%) was provided from Fluka, USA and the refined vegetable oils were from domestic edible oil companies. These chemicals were used without further purification. The purity levels of the organic solvents have been confirmed with chromatographic analysis.

\subsection{Apparatus and Procedures}

A glass-made titration-type LLE apparatus with an internal volume of about $20 \mathrm{~cm}^{3}$ was used in the present study. Its schematic diagram is shown in Fig. (1). Thermostatic water was circulated through the jacket of the equilibrium cell to control the cell's temperature to within $\pm 0.1 \mathrm{~K}$. The cell's temperature was measured with a precision mercury thermometer (2) with an uncertainty of $\pm 0.1 \mathrm{~K}$. About $10 \mathrm{~cm}^{3}$ of a liquid mixture, at a given total composition, was loaded in the equilibrium cell (1) from the top sampling port, and the 

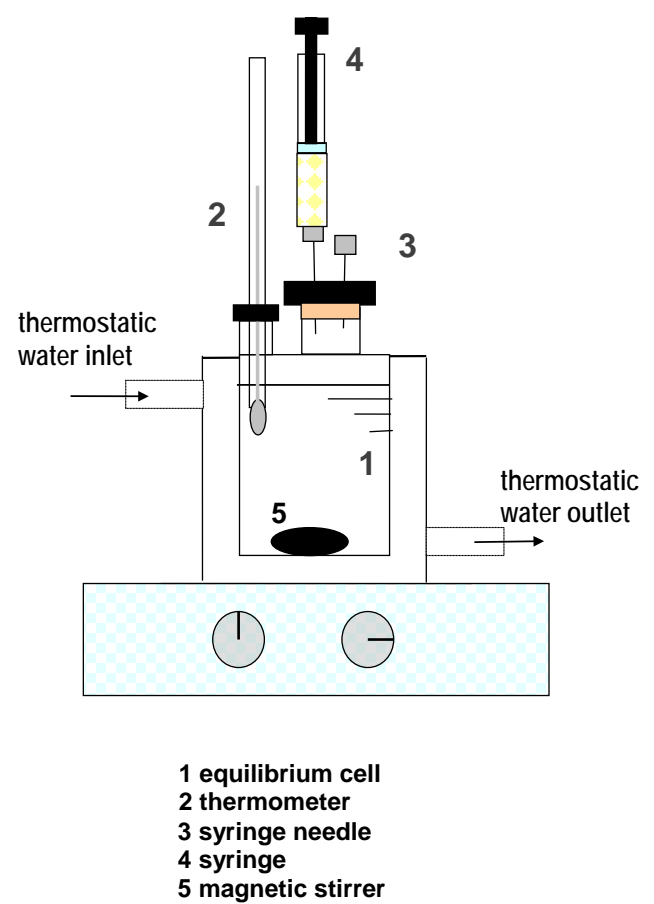

Fig. (1). Schematic diagram of LLE apparatus.

port was then sealed by a screw open top cap with a Teflon septum. A magnetic stirrer (5) vigorously agitated the liquid contents in the cell. While a syringe needle (3) was inserted through the septum to maintain the cell at atmospheric pressure during the titration process, a precision syringe (4) filled with a selected cosolvent injected the cosolvent drop by drop from the top of the cell. The volume of one drop is estimated as small as $0.02 \mathrm{~cm}^{3}$. When the cloud point was observed, the amount of the injected cosolvent was determined from the mass change of the syringe before and after the titration by a precision electronic balance, with an uncertainty of $\pm 0.1 \mathrm{mg}$. The composition of the cloud point (i.e., a point on the LLE phase boundary or the binodal curve) thus can be determined. The uncertainty of composition analysis is estimated to be better than \pm 0.001 in weight fraction.

\subsection{Experimental Results}

The LLE apparatus was used to measure the cloud points (i.e., LLE phase boundaries) for the ternary systems of sunflower + methanol with one of ten potential cosolvents, including acetone, methyl ethyl ketone, methyl acetate, ethyl acetate, methyl propionate, propylene glycol monomethyl ether acetate, dimethyl carbonate, tetrahydrofuran, methyl tert-butyl ether, and $n$-butylamine at $308.2 \mathrm{~K}$ under atmospheric pressure. Fig. (2). presents the LLE phase diagram for five selected ternary systems where the composition scales are in weight fractions. The experimental results show that all the systems behave as type-I LLE and the area of immiscibility regions decreases with the order of DMC > acetone > propylene glycol monomethyl ether acetate $>$ methyl acetate $>$ ethyl acetate $>$ methyl propionate $>$ MEK > methyl tertbutyl ether $>$ THF $>n$-butylamine. Among these investigated cosolvents, $n$-butylamine appears to be the most powerful cosolvent for enhancing the miscibility between the refined sunflower oil and methanol.

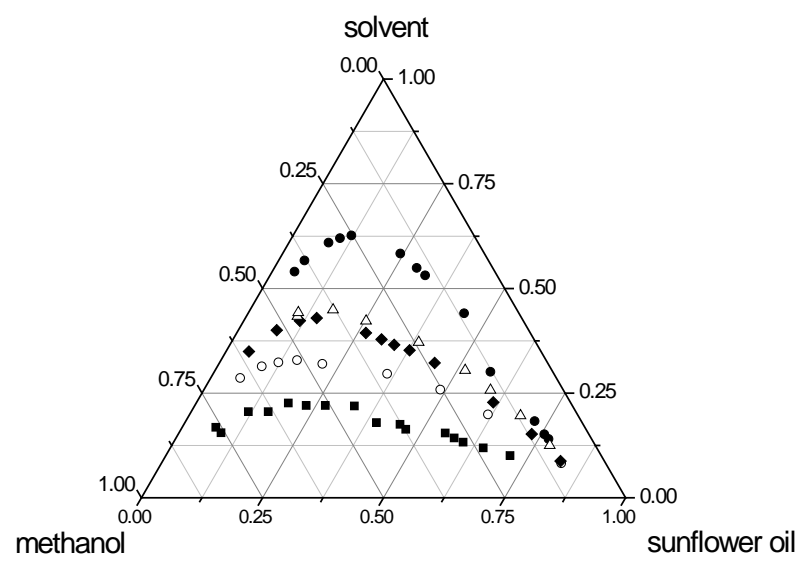

Fig. (2). LLE phase boundaries of refined sunflower oil + methanol + cosolvent at $308.2 \mathrm{~K}$ under atmospheric pressure $(\boldsymbol{\bullet}, \mathrm{DMC} ; \triangle$, ethyl acetate; $\diamond$ MEK; $\bigcirc$, THF; $\mathbf{\square}, n$-butylamine).

The temperature effects on the LLE behavior were subsequently investigated for the mixtures containing $n$ butylamine, methanol, and one of refined vegetable oils (sunflower oil, soybean oil, and canola oil) at temperatures ranging from $298.2 \mathrm{~K}$ to $318.2 \mathrm{~K}$ over atmospheric pressure. Table 1 reports the experimental results where $w_{i}$ is the weight fraction of component $i$. Fig. (3). illustrates the LLE phase boundaries of canola oil + methanol $+n$-butylamine system at different temperatures. The area of LLE regions decreases with an increase of temperature. Fig. (4). compares the binodal curves of the systems containing different refined vegetable oils at $298.2 \mathrm{~K}$, indicating that these three phase envelopes are very close.

\section{LIQUID-LIQUID PHASE EQUILIBRIUM CALCU- LATIONS}

The LLE calculations were made with the aid of the process simulation package Aspen Property. Correlative activity coefficient models were adopted to quantitatively represent the phase behavior of these investigated systems. Our experimental results of the LLE measurements were applied to determine the model parameters of two correlative solution models, the NRTL and the UNIQUAC, respectively. The definition of the NRTL is given as following:

$\ln \gamma_{i}=\frac{\sum_{j=1}^{c} x_{j} \tau_{j i} G_{j i}}{\sum_{k=1}^{c} x_{k} G_{k i}}+\sum_{j=1}^{c} \frac{x_{j} G_{i j}}{\sum_{k=1}^{c} x_{k} G_{k j}}\left[\tau_{i j}-\frac{\sum_{k=1}^{c} x_{k} \tau_{k j} G_{k j}}{\sum_{k=1}^{c} x_{k} G_{k j}}\right]$

where $G_{i j}=\exp \left(-\alpha_{i j} \tau_{i j}\right)$ and $c$ is the number of components. The UNIQUAC is defined as

$$
\begin{aligned}
& \ln \gamma_{i}=\ln \frac{\Phi_{i}}{x_{i}}+5 q_{i} \ln \frac{\theta_{i}}{\Phi_{i}}-q_{i}^{\prime} \ln t_{i}^{\prime}-q_{i}^{\prime} \\
& \sum_{j=1}^{c} \theta_{j}^{\prime} \tau_{i j} / t_{j}^{\prime}+l_{i}+q_{i}^{\prime}-\frac{\Phi_{i}}{x_{i}} \sum_{j=1}^{c} x_{j} l_{j}
\end{aligned}
$$

with 
Table 1. Experimental LLE Phase Boundaries of Sunflower Oil, Soybean Oil, or Canola Oil (1) + Methanol (2) + n-Butylamine (3) at Atmospheric Pressure

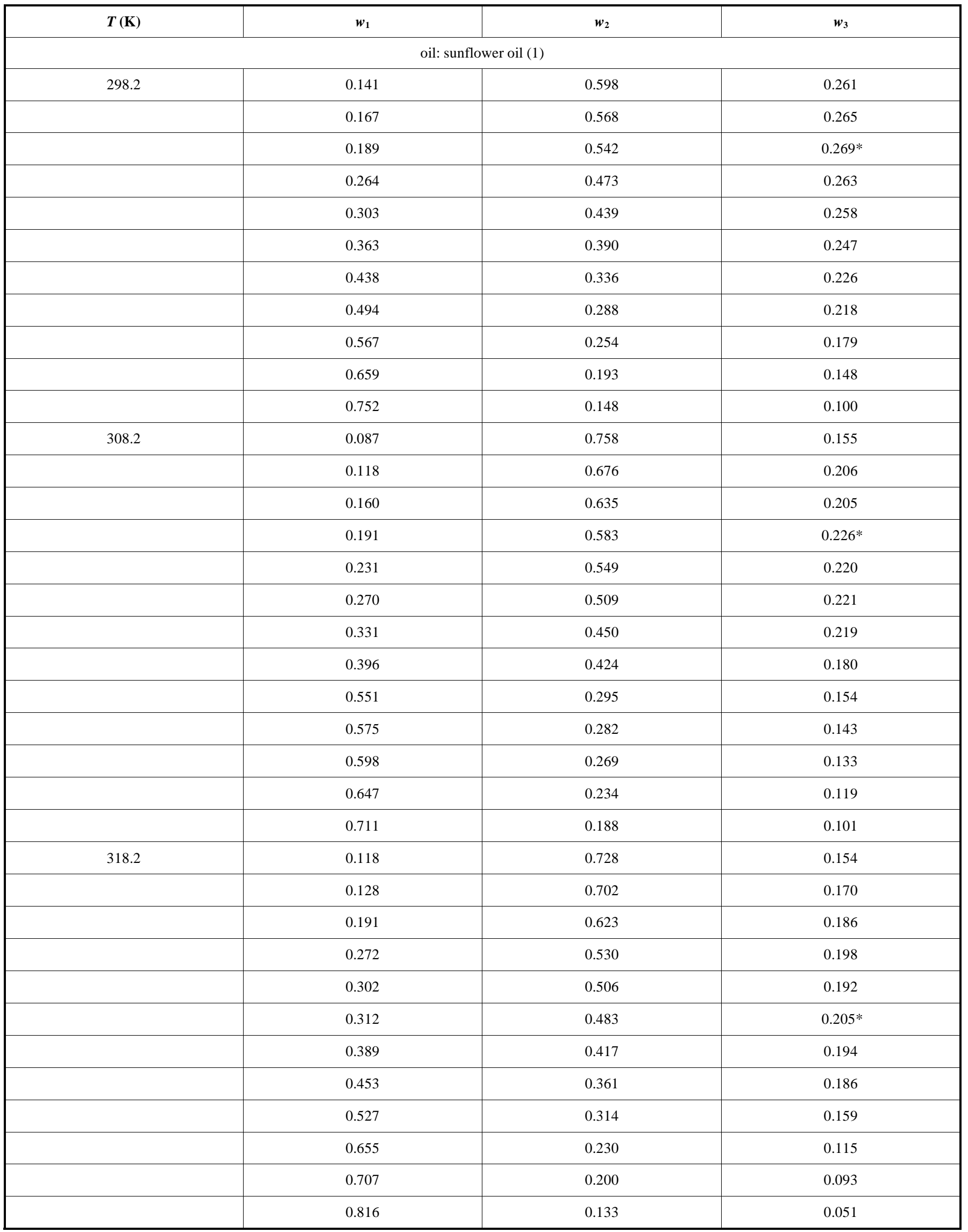


Table 1. contd...

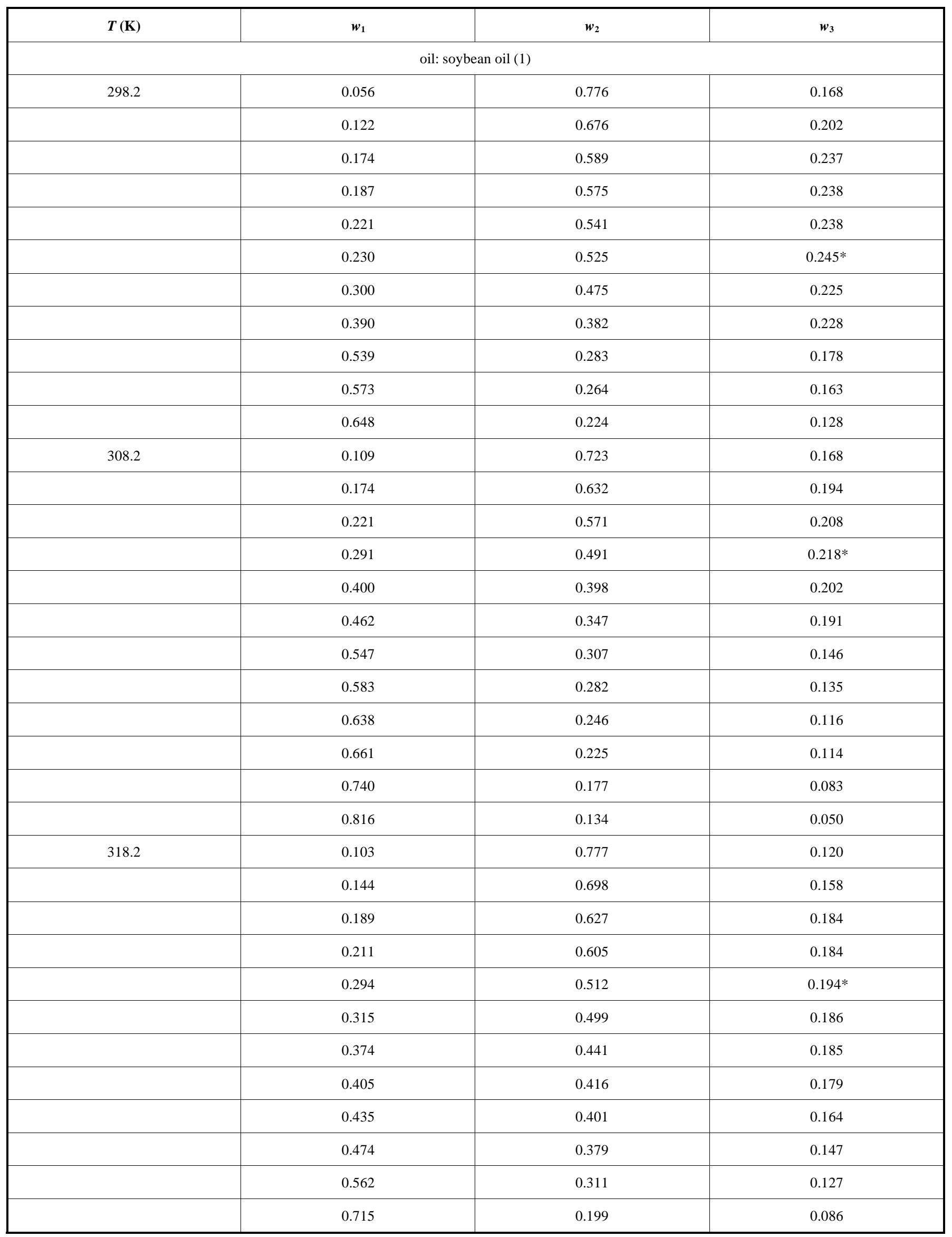


Table 1. contd.....

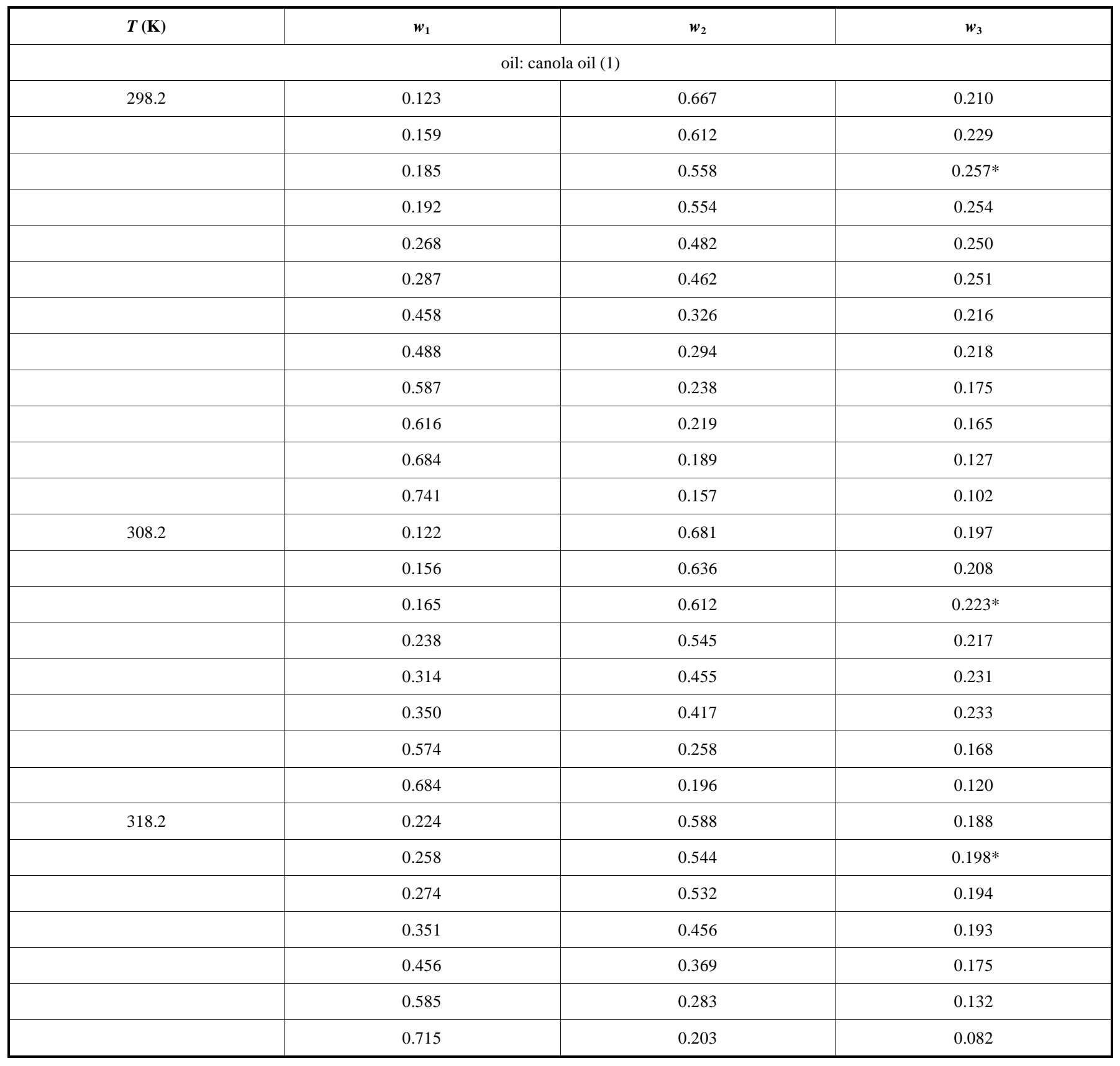

* The maximum content of a specific cosolvent (3) in the mixture.

$$
\begin{aligned}
& \Phi_{i}=\frac{r_{i} x_{i}}{\sum_{j=1}^{c} r_{j} x_{j}} \\
& \theta_{i}=\frac{q_{i} x_{i}}{\sum_{j=1}^{c} q_{j} x_{j}} \\
& \theta_{i}^{\prime}=\frac{q_{i}^{\prime} x_{i}}{\sum_{j=1}^{c} q_{j}^{\prime} x_{j}} \\
& t_{i}^{\prime}=\sum_{k=1}^{c} \theta_{k}^{\prime} \tau_{k i}
\end{aligned}
$$$$
l_{i}=5\left(r_{i}-q_{i}\right)+1-r_{i}
$$

where $r_{i}, q_{i}$, and $q_{i}^{\prime}$ are segment parameter and surface area parameters of component $i$, respectively. These structural parameters of the constituent compounds were estimated from the group-contribution method [11]. According to the typical fatty acid compositions of vegetable oils [12], the parameters of both sunflower oil and soybean oil were estimated by assuming that each oil molecule contains one oleic acid functional group and two linoleic acid groups, while each canola oil molecule contains two oleic acid groups and one linoleic acid group. Since temperature-dependent parameter $\tau_{\mathrm{ij}}$ was considered in both two models for representing the LLE phase behavior over the entire experimental temperature range, $\tau_{\mathrm{ij}}$ of the NRTL is given by 


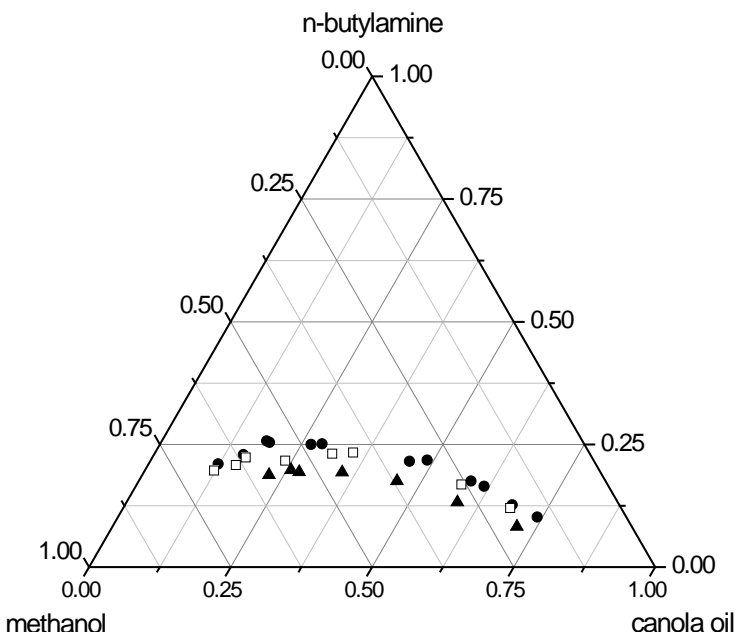

Fig. (3). LLE phase boundaries of canola oil + methanol $+n$ butylamine $(\boldsymbol{\bullet}, 298.2 \mathrm{~K} ; \square, 308.2 \mathrm{~K} ; \mathbf{\Lambda}, 318.2 \mathrm{~K})$.

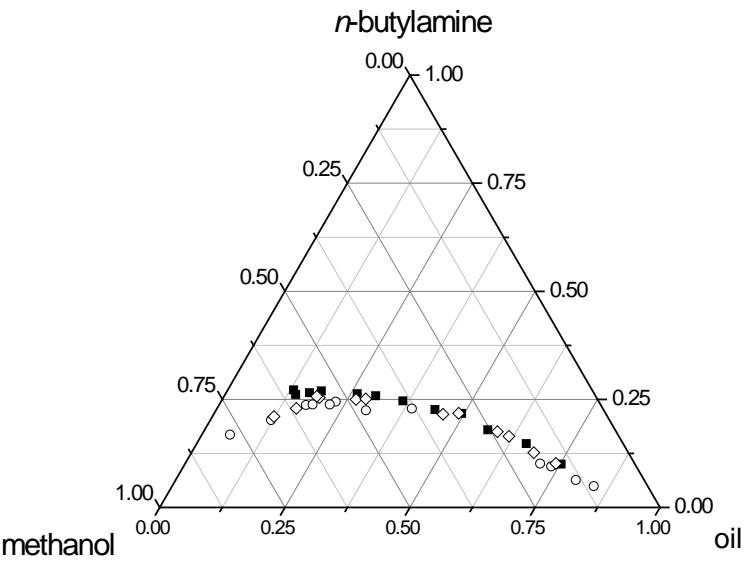

Fig. (4). LLE phase boundaries of ternary systems of methanol and $n$-butylamine plus one of three different vegetable oils at $298.2 \mathrm{~K}$ (ם, sunflower oil; $\bigcirc$, soybean oil; $\diamond$, canola oil).

$\tau_{i j}=a_{i j}+b_{i j} / T$

and that of the UNIQUAC is defined as $\tau_{i j}=\exp \left(a_{i j}+b_{i j} / T\right)$

There are three adjustable parameters $\left(a_{i j}, b_{i j}\right.$, and $\left.\alpha_{i j}\right)$ for each binary pair in the NRTL model and two adjustable parameters $\left(a_{i j}\right.$ and $\left.b_{i j}\right)$ in the UNIQUAC model. Because no experimental compositions of coexistent phases were determined simultaneously from the cloud-point measurements, the model parameters were thus adjusted manually during the parameter estimation process. The iteration trials were continued until the calculated LLE phase boundaries approached to the experimental results. Table 2 reports the determined values of the model parameters for the constituent binary pairs. A single set of model parameters appears to be sufficient for the three different vegetable oils investigated in the present study. The smoothed curves in Fig. (5). are the calculated results from the NRTL and the UNIQUAC models for sunflower oil (1) + methanol (2) $+n$-butylamine (3). Both two models reasonably describe the LLE phase behavior for this ternary system.

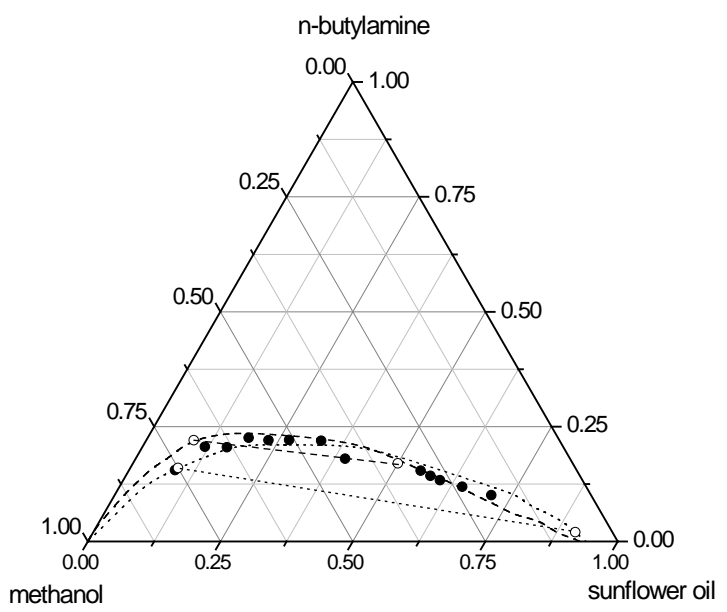

Fig. (5). Comparison of the calculated results from the NRTL and the UNIQUAC models with the experimental values of sunflower oil + methanol $+n$-butylamine at $308.2 \mathrm{~K}(\boldsymbol{O}$, experimental data; - , calculated from the NRTL; - - - , calculated from the UNIQUAC; . , calculated end points of tie line).

Table 2. Parameters of the NRTL and the UNIQUAC Models for the Constituent Binaries ${ }^{\mathrm{a}}$

\begin{tabular}{|c|c|c|c|c|c|c|}
\hline system & $i-j$ & $\alpha_{\mathrm{ij}}$ & $a_{\mathrm{ij}}^{\mathrm{b}}$ & $a_{\mathrm{ji}}^{\mathrm{b}}$ & $b_{\mathrm{ij}}{ }^{\mathrm{b}}(\mathrm{K})$ & $b_{\mathrm{ji}}^{\mathrm{b}}(\mathrm{K})$ \\
\hline oil $(1)+$ methanol $(2)+$ & $1-2^{\mathrm{a}}$ & 0.30 & -0.4609 & -0.35 & -111.8072 & 2824.3631 \\
\hline \multirow[t]{2}{*}{$n$-butylamine (3) } & $1-3$ & 0.30 & -4.2496 & -0.55 & -999.2197 & 1766.7037 \\
\hline & $3-2$ & 0.47 & -0.3074 & -0.35 & -607.7037 & 131.5529 \\
\hline oil $(1)+$ methanol $(2)+$ & $1-2^{\mathrm{a}}$ & - & -0.4500 & -0.01 & -418.6907 & 1.6813 \\
\hline \multirow[t]{2}{*}{$n$-butylamine (3) } & $1-3$ & - & -0.2312 & -0.01 & -90.8075 & 34.4796 \\
\hline & $3-2$ & - & -0.7227 & -0.01 & 476.7736 & -241.0775 \\
\hline
\end{tabular}

${ }^{\mathrm{a}}$ The values of parameters for the binaries containing any one of the studied refined vegetable oils are assigned to be identical, regardless of species of oils.

${ }^{\mathrm{b}} \tau_{i j}=a_{i j}+\frac{b_{i j}}{T}$ for the NRTL model; $\tau_{i j}=\exp \left(a_{i j}+\frac{b_{i j}}{T}\right)$ for the UNIQUAC model 


\section{CONCLUSIONS}

Ten potential cosolvents have been tested to enhance the mutual solubilities between refined sunflower oil and methanol with cloud point method. $n$-Butylamine was found to be a preferable cosolvent to homogenize the mixtures of the oil and methanol. The temperature effects on the LLE phase boundaries have also been investigated for ternary mixtures containing $n$-butylamine, methanol, and one of three refined vegetable oils (sunflower oil, soybean oil, and canola oil) at temperatures ranging from $298.2 \mathrm{~K}$ to $318.2 \mathrm{~K}$ over atmospheric pressure. The experimental results have been used to determine the model parameters of the NRTL and the UNIQUAC models for the constituent binaries. The results obtained from this study are useful in the process development for producing biodiesel from a diversity of plant oils and methanol in the presence of selected cosolvents.

\section{ACKNOWLEDGEMENT}

The authors gratefully acknowledged the financial support from the National Science Council, Taiwan, through grant No. NSC96-ET-7-011-001-ET.

\section{REFERENCES}

[1] F. Ma and M.A. Hanna, "Biodiesel production: a review", Bioresource Technol., vol. 70, pp. 1-15, 1999.

[2] L.C. Meher, D. Vidya Sagar, and S.N. Naik, "Technical aspects of biodiesel production by transesterification- a review", Renew. Sust. Energ. Rev., vol. 10, pp. 248-268, 2006.
[3] A. Demirbas, "Progress and recent trends in biofuels", Prog. Energ. Combust., vol. 33, pp. 1-18, 2007.

[4] T.M. Letcher, "Ternary liquid-liquid phase diagram for diesel fuel blends", S. Afr. J. Sci., vol. 76, pp. 130-132, 1980.

[5] T.M. Letcher, "Diesel blend for diesel engine", S. Afr. J. Sci., vol. 79, pp. 4-7, 1983.

[6] D.G.B. Boocock, S.K. Konar, V. Mao, and H. Sidi, "Fast onephase oil-rich processes for the preparation of vegetable oil methyl esters", Biomass Bioenerg., vol. 11, pp. 43-50, 1996.

[7] T. Cerce, S. Peter, and E. Weidner, "Biodiesel transesterification of biological oils with liquid catalysts: thermodynamic properties of oil-methanol-amine mixture", Ind. Eng. Chem. Res., vol. 44, pp. 9535-9541, 2005.

[8] K. Maeda, H. Kuramochi, T. Fujimoto, Y. Asakuma, K. Fukui, M. Osako, K. Nakamura, and S. Sakai, "Phase equilibrium of biodiesel compounds for the triolein + palmitic acid + methanol system with dimethyl ether as cosolvent", J. Chem. Eng. Data, vol. 53, pp. 973977, 2008.

[9] H. Renon and J.M. Prausnitz, " Local compositions in thermodynamic excess functions for liquid mixtures", AIChE J., vol. 14, pp. $135-144,1968$.

[10] D.S. Abrams and J.M. Prausnitz, "Statistical thermodynamics of liquid mixtures: a new expression for the excess Gibbs free energy of partly or completely miscible systems", AIChE J., vol. 21, pp. 116-128, 1975.

[11] A. Fredenslund, J. Gmehling, and P. Rasmussen, Vapor-liquid equilibria using UNIFAC: a group-contribution method. Amsterdam: Elsevier, 1977.

[12] E. Lotero, Y. Liu, D.E. Lopez, K. Suwannakarn, D.A. Bruce, and J.G. Goodwin, Jr., "Synthesis of biodiesel via acid catalysis", Ind. Eng. Chem. Res., vol. 44, pp. 5353-5363, 2005.

(C) Lee et al.; Licensee Bentham Open.

This is an open access article licensed under the terms of the Creative Commons Attribution Non-Commercial License (http://creativecommons.org/licenses/by-nc/3.0/) which permits unrestricted, non-commercial use, distribution and reproduction in any medium, provided the work is properly cited. 